\title{
Health and social impact assessment of the South East Queensland Regional Plan (2005-2026)
}

\author{
Kate J. Copeland ${ }^{\mathrm{A}, \mathrm{C}}$ and Andrea M. Young ${ }^{\mathrm{B}}$ \\ ${ }^{\mathrm{A}}$ Capital Works and Asset Management Branch, \\ Queensland Health \\ BAndrea Young Planning Consultants

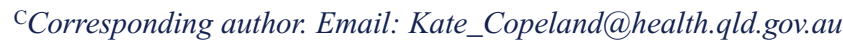

\begin{abstract}
A health and social impact assessment of the South East Queensland Regional Plan was undertaken in 2005 (Queensland Government, 2005). It is one of few attempts nationally and globally to apply health and social impact assessment to a regional planning process. The assessment methodology builds on existing evidence-based research, methodologies and the combined professional experience of both health and social impact assessment practices in Queensland. The approach adds further strength and rigour to planning strategies to enhance the health and well-being of communities. The way the South East Queensland Regional Plan is implemented, and how the plan influences access to jobs, education, affordable housing and social infrastructure, and the achievement of social inclusion and connectedness within communities, will be central to future health and well-being of people in South East Queensland.
\end{abstract}

In October 2004, the Draft South East Queensland Regional Plan was released and circulated for comment. It proposed a new framework for legislated management of urban growth in South East Queensland, the population of which is expected to grow by 1.05 million people by 2026 . Health and social planners took the opportunity to proactively progress the inclusion of health and well-being as a consideration in future planning. Queensland Health's Population Health Branch had been an active proponent of health impact assessment (HIA), ${ }^{1,2}$ while the Department of Communities and local government agencies used social impact assessment.
The health and social impact assessment merged both the HIA and social impact assessment methodologies into a single, combined impact assessment, to enable a broader understanding of the potential impacts of the proposed South East Queensland Regional Plan ${ }^{3}$ on health and wellbeing. It was a collaborative effort between Queensland Health, the Department of Communities, the Office of Urban Management and representatives from local government community and social planners, and it was led by a social planning consultant.

The use of the combined methodology to assess the potential impacts of the South East Queensland Regional Plan allowed input into the Regional Plan while it was still in its draft stage. This collaboration also provided a higher profile for consideration of factors ${ }^{4-6}$ which impact either positively or negatively on health and well-being outcomes, and this helped to inform the Plan to support and promote the future health and well-being of South East Queensland population.

Key objectives achieved by the project were to:

- ensure the South East Queensland Regional Plan included consideration of health and well-being in the Region

- identify risks associated with the implementation of the Plan

- identify strategies that would enhance health and wellbeing as the South East Queensland population increased and the plan was implemented

- develop tools that supported the ongoing consideration of health and well-being in planning activities, both in South East Queensland and other locations

- trial combining health and social impact assessment methodologies and consider its appropriateness for future planning activities,

- inform the planning of health services in South East Queensland to meet the needs of the anticipated population growth.

\section{The approach}

Health and social well-being have much in common, as indicated in the World Health Organization's definition of health: ${ }^{7}$

Health is a state of complete physical, mental and social wellbeing and not merely the absence of disease. 
Health status is influenced by a complex interaction of social, economic, environmental, behavioural and genetic factors. A safe environment, adequate income, meaningful social roles, secure housing, higher levels of education and social support are all associated with better health and well-being.

Both HIA and social impact assessment adopt similar methodologies to enable the benefits of an initiative to be enhanced and potential negative impacts to be prevented or minimised at the design stage. Both processes culminate in proposal modifications, and a management plan designed to enhance, reduce or avoid identified risks. In this project, both impact assessments benefited from merging their methodologies.

The project commenced with a broad scoping of issues through a rapid impact assessment workshop attended by a cross section of health and social specialists. This process enabled some immediate input into the development of the Draft Regional Plan. The issues identified were subsequently investigated in a more detailed comprehensive impact assessment, undertaken after the Plan was released for public consultation.

As time and resourcing did not allow community engagement, a heavy reliance was placed on available information from experienced professionals and academics for the assessment.

\section{Findings}

The combined assessment reported findings at a broad level, reflecting the broad nature of the strategies in the Draft South East Queensland Regional Plan. It concluded that the specific impacts arising from the Regional Plan were difficult to confirm and would depend on how its general intent (eg for strong communities and greater accessibility) was to be implemented. It was this that would determine the outcomes in terms of impacting on access to jobs, education, affordable housing, social infrastructure and social connectedness.

Income is one of the central determinants of health and well-being, with the equitable distribution of economic development and access to jobs in the region of importance. Achievement of the Regional Plan's aspirations for the distribution of jobs at key locations within the region is important to community well-being.
Housing affordability has an important impact on the disposable income for households, with the supply of affordable housing identified as an issue in the region. Existing patterns of social polarisation, where lower income households have gravitated to outer urban areas, highlight the need to address affordable housing supply across the region. The impact assessment identified the potential impact of transit-oriented development on existing affordable housing stock, especially where located in older urban areas.

Urban consolidation, and in particular transit-oriented developments, were considered to improve outcomes for accessibility and provide an opportunity to promote healthy and active lifestyles through improved planning supporting walking and cycling.

Social support and relationships, and meaningful participation in society, are linked to both individual and community health. With the high levels of regional population growth expected, the importance of supporting the formation of these roles and relationships through investment in such infrastructure as community facilities, community services and community development programs was highlighted.

Further challenges were identified in the significant changes that can be expected in communities targeted for growth, in particular communities in the Western corridor and infill sites identified for transit-oriented developments. Community participation in these processes of change was identified as an important vehicle through which to help manage both positive and negative impacts of change on a community's sense of identity and social cohesion.

The study identified the need for special attention to the implications of an ageing population in South East Queensland, particularly in communities with concentrated ageing populations such as coastal and rural areas. Priorities included planning for the high proportion of older people living alone, acknowledging the related risks of social isolation. The needs of ageing among culturally and linguistically diverse people are also poorly understood.

Other issues included the need to manage potential environmental health impacts associated with land-use conflicts (eg urban and rural uses) within the urban foot-

Table 1. Tools developed in the combined health and social impact assessment of the South East Queensland Regional Plan

TOOL 1 Health, well-being and the urban environment - a summary of known relationships

TOOL 2 A baseline report of existing health and social conditions in South East Queensland

TOOL 3 Analysis of the health and social impacts of the South East Queensland Regional Plan

TOOL 4 An outline of health and well-being considerations for planning instruments under the Regional Plan

TOOL 5 An outline of considerations for health and social impact assessment of transport infrastructure proposals 
print during the transition of some of these areas to urbanisation. The impacts of total water cycle management systems, while not well understood, were thought to include equity impacts associated with cost shifting, as well as ensuring capacity for individuals to manage new water collection systems safely and effectively.

\section{Outputs}

The health and social impact assessment captured the opportunity to resource practitioners charged with the responsibility of implementing the Regional Plan with a series of tools that provide practical guidance on how to integrate health and social considerations in their work. The tools target a range of regional planning processes, including the preparation of Local Growth Management Strategies and Structure Plans, as well as more generalised planning processes.

The tools developed can be accessed at the website address provided at the end of this article and are listed in Table 1.

As a result of the project, significant relationships were also developed between several of the stakeholders including Queensland Health, the Department of Communities, the Office of Urban Management and local government. Areas of common interest in urban development and management were discovered through the project, resulting in the strengthened understanding and ability to work together for the agencies involved. Additional information on the health and social impact assessment for South
East Queensland Regional Plan can be found at: www.health.qld.gov.au/partners/seq/seq_plan.asp.

\section{Acknowledgements}

Lisa Pollard, Community Engagement and Development Policy Unit, Strategic Policy, Department of Communities; Simone Cuers, Office of Urban Management; Sophie Dwyer, Population Health Branch, Queensland Health; Shannon McKeirnan, Environmental Health, Gosford City Council.

\section{References}

1. Mahoney M, Durham G. Health impact assessment: a tool for policy development in Australia. Burwood, Deakin University, 2002. Available at www.hbs.deakin.edu.au/HealthSci/ Research/HIA, accessed August 2007.

2. Taylor L, Quigley R. Health impact assessment: a review of reviews by health department agency, 2002. Available at www.hda-online.org.uk/evidence, accessed August 2007.

3. South East Queensland Regional Plan 2005-2026. Brisbane: Queensland Government Office of Urban Management, 2005.

4. Townson M. Health and wealth: how social and economic factors affect our well-being. Ottawa: The Canadian Centre for Policy Alternatives, 1999.

5. Wilkinson R, Marmot M, editors. The solid facts: social determinants of health. 2nd ed. Eds:. Copenhagen: World Health Organization, 2003.

6. Butterworth I. The relationship between the built environment and well-being: a literature review. Melbourne: Victorian Health Promotion Foundation, 2001.

7. Constitution of the World Health Organization. Geneva: World Health Organization, 1946. 